OPEN ACCESS

Approved by:

Frontiers Editorial Office,

Frontiers Media SA, Switzerland

${ }^{*}$ Correspondence:

Shu-Miaw Chaw

smchaw@sinica.edu.tw

TORCID:

Chung-Shien Wu

orcid.org/0000-0003-0000-6253

Edi Sudianto

orcid.org/0000-0002-0771-0385

Shu-Miaw Chaw

orcid.org/0000-0003-2499-7071

Hui-Lung Chiu

orcid.org/0000-0002-3104-807X

Chih-Ping Chao

orcid.org/0000-0002-5282-0858

$\mp$ These authors have contributed

equally to this work

Specialty section:

This article was submitted to

Plant Systematics and Evolution,

a section of the journal

Frontiers in Plant Science

Received: 07 September 2021 Accepted: 08 September 2021

Published: 01 October 2021

Citation:

Wu C-S, Sudianto E, Chiu H-L, Chao C-P and Chaw S-M (2021)

Corrigendum: Reassessing Banana

Phylogeny and Organelle Inheritance Modes Using Genome Skimming

Data. Front. Plant Sci. 12:771777.

doi: 10.3389/fp/s.2021.771777

\section{Corrigendum: Reassessing Banana Phylogeny and Organelle Inheritance Modes Using Genome Skimming Data}

\author{
Chung-Shien Wu ${ }^{1 \neq \neq}$, Edi Sudianto ${ }^{1 t \neq}$, Hui-Lung Chiu ${ }^{2 t}$, Chih-Ping Chao ${ }^{3 t}$ and \\ Shu-Miaw Chaw ${ }^{1 *+}$ \\ ${ }^{1}$ Biodiversity Research Center, Academia Sinica, Taipei, Taiwan, ${ }^{2}$ Plant Germplasm Division, Taiwan Agricultural Research \\ Institute, Taichung, Taiwan, ${ }^{3}$ Taiwan Banana Research Institute, Pingtung, Taiwan
}

Keywords: banana, genome skimming, cytoplasmic inheritance, nrDNA, mitogenome, plastome

\section{A Corrigendum on}

Reassessing Banana Phylogeny and Organelle Inheritance Modes Using Genome Skimming Data

by Wu, C.-S., Sudianto, E., Chiu, H.-L., Chao, C.-P., and Chaw, S.-M. (2021). Front. Plant Sci. 12:713216. doi: 10.3389/fpls.2021.713216

In the original article, in the section Mitochondrial Gene Repertoire of Musaceae, the sentence "They also lack the intron in $c c m F n$ (Figure 4B)." should have read "They also lack the intron in $c c m F c$ (Figure 4B)."

In the associated caption to Figure 4B, "(B) Intron loss from $c c m F n$." should have read "(B) Intron loss from $c \mathrm{cmFc}$."

The authors apologize for this error and state that this does not change the scientific conclusions of the article in any way. The original article has been updated.

Publisher's Note: All claims expressed in this article are solely those of the authors and do not necessarily represent those of their affiliated organizations, or those of the publisher, the editors and the reviewers. Any product that may be evaluated in this article, or claim that may be made by its manufacturer, is not guaranteed or endorsed by the publisher.

Copyright $\odot 2021 \mathrm{Wu}$, Sudianto, Chiu, Chao and Chaw. This is an open-access article distributed under the terms of the Creative Commons Attribution License (CC BY). The use, distribution or reproduction in other forums is permitted, provided the original author(s) and the copyright owner(s) are credited and that the original publication in this journal is cited, in accordance with accepted academic practice. No use, distribution or reproduction is permitted which does not comply with these terms. 